\title{
Riscos do investidor-anjo e limites de sua responsabilidade em startups
}

\author{
Risks of the angel investor and limits of his responsibility in startups \\ Riesgos del inversor ángel y límites de su responsabilidad en las startups
}

Torben Fernandes Maia

ORCID: https://orcid.org/0000-0003-3053-3062 Universidade de São Paulo, Brasil

E-mail: torben@paulomaia.adv.br

Paulo Antônio Maia e Silva Junior

ORCID: https://orcid.org/0000-0003-0846-0952 Universidade Federal da Paraíba, Brasil

E-mail: paulojr@paulomaia.adv.br

José Cândido da Silva Nóbrega

ORCID: https://orcid.org/0000-0002-0976-3763

Universidade Federal de Campina Grande, Brasil

E-mail: jcandidosn@uol.com.br

Francisco das Chagas Bezerra Neto

ORCID: https://orcid.org/0000-0001-6232-4383

Universidade Federal de Campina Grande, Brasil

E-mail: chagasneto237@gmail.com

\begin{abstract}
Resumo
O presente estudo vislumbra analisar alguns apontamentos acerca dos riscos do investidor-anjo e limites de sua responsabilidade em startups. Nessa perspectiva, este artigo, através da pesquisa exploratória, de natureza qualitativa, método dedutivo, coleta de dados documental e bibliográfica, procedeu-se de modo a realizar uma análise minuciosa do arcabouço normativo e jurisprudencial que trata acerca das startups. Não obstante, foi pontuado a extrema relevância que as startups possuem para o cenário econômico e social, e o papel que o investidor-anjo desempenha dentro desse cenário. Dessa maneira, diante da problemática exposta, buscou-se, tendo como base a axiologia constitucional, e partindo para uma hermenêutica sistêmica com a legislação civil e normas esparsas, analisar e ponderar a distribuição de responsabilidades entre investidor e investido dentro do que a legislação orienta sobre como deve ser. Ademais, foi destacado as questões particulares das startups, principalmente no tocante a possibilidade de falência desta empresa ser ainda maior, dada a ausência de precedentes e de um modelo de negócios já consolidado, em que os fundadores irão atuar sobre terreno completamente desconhecido e sem parâmetros de sucesso a ser seguido.
\end{abstract}

Palavras-chave: Riscos; Investidor-anjo; Startups.

\begin{abstract}
The present study analyzes some notes about the risks of the angel investor and the limits of his responsibility in startups. In this perspective, this article, through exploratory research, of qualitative nature, deductive method, collection of documentary and bibliographic data, proceeded in order to carry out a thorough analysis of the normative and jurisprudential framework that deals with startups. Nevertheless, the extreme need that startups have for the economic and social scenario, and the role that the angel investor plays within this scenario, was pointed out. Thus, in view of the exposed problem, we sought, based on constitutional axiology, and starting with a systemic hermeneutics with civil legislation and sparse norms, analyzing and considering the distribution of responsibilities between investor and invested within what the legislation guides about how it should be. In addition, it was highlighted as particular issues of startups, especially not considering the possibility of bankruptcy of this company being even greater, given the absence of precedents and a business model already consolidated, in which the founders will act on completely unknown terrain and without parameters success to be followed.
\end{abstract}

Keywords: Scratchs; Angel investor; Startups.

\section{Resumen}

El presente estudio analiza algunas notas sobre los riesgos del inversor ángel y los límites de su responsabilidad en las startups. En esta perspectiva, este artículo, a través de una investigación exploratoria, de carácter cualitativo, método deductivo, recolección de datos documentales y bibliográficos, procedió a realizar un análisis exhaustivo del marco normativo y jurisprudencial que se ocupa de las startups. No obstante, se señaló la extrema necesidad que tienen las startups por el escenario económico y social, y el papel que juega el ángel inversor dentro de este escenario. Así, ante la problemática expuesta, se buscó, con base en la axiología constitucional, y partiendo de una hermenéutica sistémica 
con legislación civil y normativa dispersa, analizar y ponderar el reparto de responsabilidades entre inversionista e invertido dentro de lo que orienta la legislación sobre cómo debe ser. Además, se destacó como cuestiones particulares de las startups, sobre todo sin considerar que la posibilidad de quiebra de esta empresa sea aún mayor, dada la ausencia de precedentes y un modelo de negocio ya consolidado, en el que los fundadores actuarán en un terreno completamente desconocido y sin parámetros de éxito a seguir.

Palabras clave: Arañazos; Inversor de Angeles; Inauguración.

\section{Introdução}

A distinção entre a pessoa jurídica e os sócios, ou terceiros com quem ela venha desenvolver relações, é milenar, cuja origem remonta até o Direito Romano, povo que já partilhava da ideia de independência e unidade das "corporações" e “fundações" (Dantas, 2018).

$\mathrm{O}$ ordenamento jurídico brasileiro adotou tal ensinamento, conferindo autonomia às pessoas jurídicas em relação às pessoas que a compõem e a instituíram. Segundo Renato Becho (2014), embora o Código Civil de 2002 não tenha expressamente afirmado esse raciocínio, é possível concluir dessa maneira, vez que através do art. 50 desta legislação, ao prever uma exceção para a despersonalização, há que se concluir que a personalização é a regra.

Nesse sentido, as empresas constituem relações jurídicas autônomas, que embora representadas pelos seus membros, dirigentes ou administradores, com eles não se confundem, podendo contrair obrigações nas diversas searas da vida em sociedade: trabalhista, consumerista, tributária, entre outas.

Além disso, a maneira como ela se relaciona, firma compromissos, torna-se credora e obrigada perante esses vínculos, torna-a responsável por tudo aquilo que assumir nessa qualidade, de modo que diante de eventual prejuízo ou inadimplemento dessas obrigações, poderá vir a ser forçada a honrar com o combinado, sempre nos limites do seu patrimônio, como regra.

Contudo, existem casos em que a legislação possibilita, de maneira excepcional, ignorar essa regra, para que o patrimônio de terceiros seja envolvido como responsável pelos atos e omissões da pessoa jurídica.

Trata-se do instituto da desconsideração da personalidade jurídica no Brasil, que é regulado por um conjunto de legislações, dentre as quais se destaca o art. 50 do Código Civil de 2002, o art. 28, caput e $\$ 5^{\circ 2}$ do CDC (Lei 8.078 de 1990), o art. $18^{3}$ da Lei 12.529 de 2011, popularmente conhecida como a Lei Antitruste brasileira e com previsão de procedimento no CPC/15, através dos arts. 133 a 137.

Há que se diferenciar, ainda, desconsideração de despersonalização. O primeiro instituto consiste em manter constituída a pessoa jurídica, mas excepcionalmente desrespeitar a sua autonomia e independência, para alcançar o patrimônio das pessoas físicas que a compõem, especificamente no eventual caso concreto, desde que preenchidos os requisitos da respectiva legislação. Na segunda, há um desaparecimento e desconstituição definitiva da personalidade, que deixa de existir para o mundo jurídico, em virtude da perda superveniente das suas condições de existência, seja pela invalidade do contrato social ou pela dissolução da sociedade (Comparato \& Salomão Filho, 2008).

\footnotetext{
${ }^{1}$ Art. 50. Em caso de abuso da personalidade jurídica, caracterizado pelo desvio de finalidade, ou pela confusão patrimonial, pode o juiz decidir, a requerimento da parte, ou do Ministério Público quando lhe couber intervir no processo, que os efeitos de certas e determinadas relações de obrigações sejam estendidos aos bens particulares dos administradores ou sócios da pessoa jurídica.

${ }^{2}$ Art. 28. O juiz poderá desconsiderar a personalidade jurídica da sociedade quando, em detrimento do consumidor, houver abuso de direito, excesso de poder, infração da lei, fato ou ato ilícito ou violação dos estatutos ou contrato social. A desconsideração também será efetivada quando houver falência, estado de insolvência, encerramento ou inatividade da pessoa jurídica provocados por má administração.

$\S 5^{\circ}$ Também poderá ser desconsiderada a pessoa jurídica sempre que sua personalidade for, de alguma forma, obstáculo ao ressarcimento de prejuízos causados aos consumidores.

${ }^{3}$ Art. 34. A personalidade jurídica do responsável por infração da ordem econômica poderá ser desconsiderada quando houver da parte deste abuso de direito, excesso de poder, infração da lei, fato ou ato ilícito ou violação dos estatutos ou contrato social. Parágrafo único. A desconsideração também será efetivada quando houver falência, estado de insolvência, encerramento ou inatividade da pessoa jurídica provocados por má administração.
} 
Consoante Coelho e Garrido (2016), a responsabilidade societária vem sendo cada vez mais desconsiderada no Brasil. Embora ocorra com mais frequência no direito trabalhista e consumidor, que opera sobre a presunção relativa de hipossuficiência do trabalhador e consumidor, isso é uma prática que vem alcançando cada vez mais o Direito Empresarial.

É em decorrência desse fato que a análise jurisprudencial acerca de como o judiciário brasileiro se comporta diante da responsabilidade civil sobre as empresas, e a maneira como isso pode alcançar e colocar em risco o investidor-anjo em startups, é que foram escolhidos julgados especiais, que podem nortear a maneira como isso pode afetar eventual operação de financiamento nessa modalidade.

A análise do nicho de startups como uma modalidade apartada das demais empresas se justifica na medida em que é da natureza dessas corporações a possibilidade de falência ser ainda maior, dada a ausência de precedentes e de um modelo de negócios já consolidado, em que os fundadores irão atuar sobre terreno completamente desconhecido e sem parâmetros de sucesso a ser seguido. Somado a isso, a característica de informalidade, marca presente desse ecossistema, em que parte considerável dos fundadores estão atuando pela primeira vez no mercado empresarial, torna a viabilidade da empresa ainda mais instável.

Em atendimento aos objetivos propostos, será realizada uma pesquisa exploratória, que tem por objetivo proporcionar uma maior familiaridade com o problema. Sem a perspectiva de esgotamento do tema, tratar-se-á, sobretudo, acerca dos Riscos do investidor-anjo e limites de sua responsabilidade em startups. Ademais, se utilizará do método de abordagem dedutivo, uma vez que se buscará os resultados a partir da análise geral até concluir de maneira particular a hipótese. Quanto à natureza da pesquisa, esta será qualitativa, buscar-se-á analisar e interpretar os institutos do Direito Empresarial, com o intuito de tecer considerações sobre as peculiaridades que envolvem cada uma das relações jurídicas, as quais são regidas por legislações especiais e próprias, e que em alguns momentos podem até ser conflituosas

Quanto ao método de procedimento, atribuir-se-á o método monográfico, partindo de um estudo profundo sobre as startups, que podendo esta pesquisa ser considerada representativa de muitos outros ou mesmo de todos os casos semelhantes. Além do mais, quanto aos procedimentos técnicos, se delineará o presente estudo por meio de pesquisa bibliográfica e documental, tendo em vista que se buscará, através da renomada doutrina do direito e periódicos especializados, bem como através da interpretação das leis, a solução para impulsionar o crescimento econômico.

\section{Desenvolvimento}

O direito brasileiro optou por segmentar a relação consumerista, a qual através da Lei no 8.078/1990 criou um microssistema, o qual visa tutelar esses vínculos, visando equalizar as desigualdades, partindo da presunção de hipossuficiência do consumidor em relação ao fornecedor.

Assim, este sistema especial, dotado de regramentos específicos, incide todas as vezes em que uma relação de consumo se configura, atraindo todos os ditames impostos pela norma especial. Nesse sentido, é preciso que exista em uma ponta uma pessoa física ou jurídica, que esteja adquirindo ou utilizando um produto ou serviço na qualidade de destinatário final, segundo a inteligência do art. $2^{\circ}$ do Código de Defesa do Consumidor (CDC).

Do outro lado dessa conexão terá um fornecedor, o qual poderá ser qualquer pessoa física ou jurídica, de natureza pública ou privada, estrangeira ou nacional, até mesmo entes despersonalizados, desde que atuem em "atividade de produção, montagem, criação, construção, transformação, importação, exportação, distribuição ou comercialização de produtos ou prestação de serviços”, segundo o art. $3^{\circ}$ dessa mesma legislação.

Nas palavras de Cláudia Lima Marques, haverá incidência do CDC, sempre que houver: 
[...] contratos firmados entre o fornecedor e o consumidor não profissional, e entre o fornecedor e o consumidor, que pode ser um profissional, mas que, no contrato em questão, não visa lucro, pois o contrato não se relaciona com a sua atividade profissional, seja este consumidor pessoa física ou jurídica. (Marques, 2006, p. 338).

Através do CDC, houve a criação da Política Nacional da Relação de Consumo, a qual parte do reconhecimento e presunção de vulnerabilidade do consumidor, para a criação de ações governamentais para a proteção desse agente, seja através de iniciativas diretas, incentivos ou mediante a presença do Estado.

Desse modo, dentre os diversos dispositivos que atuam em proteção do consumidor, destaca-se para o presente trabalho o instituto da desconsideração da personalidade jurídica do fornecedor nas relações do consumo, através do art. $28^{\circ}$ do CDC:

Art. 28. O juiz poderá desconsiderar a personalidade jurídica da sociedade quando, em detrimento do consumidor, houver abuso de direito, excesso de poder, infração da lei, fato ou ato ilícito ou violação dos estatutos ou contrato social. A desconsideração também será efetivada quando houver falência, estado de insolvência, encerramento ou inatividade da pessoa jurídica provocados por má administração. (Brasil, 1990).

Visando garantir a efetiva reparação dos danos sofridos pelo consumidor, de previsão no inciso IV do art. $6^{\circ}$, foi positivada a relativização da personalidade jurídica do fornecedor em sua modalidade mais ampla, o que a doutrina chama de Teoria Menor da desconsideração da personalidade jurídica (Tartuce, 2016).

Todavia, quando se parte para o ecossistema das startups, diante dos casos em que essas empresas houverem feito contrato de participação, nos moldes da Lei Complementar nº 155/16, para operar um investimento-anjo e receber recursos, como fica a situação do angel perante eventual litígio consumerista, em que houver a suscitação do incidente de desconsideração da personalidade jurídica para alcançar o seu patrimônio?

Segundo a $L C \mathrm{n}^{\circ} 155$, norma especial e mais recente do que o CDC, propõe-se a regular especificamente a situação do investidor-anjo quando realizar financiamento de empresas na modalidade de um contrato de participação. Para isso, através do texto legal, é imposto uma série de requisitos, com limitações para esse agente, para que possa ao final, gozar de algumas prerrogativas legais.

Dentre os diversos dispositivos, chama atenção a regra disposta no inciso II, do $\S 4^{\circ}$ do art. $61-\mathrm{A}^{4}$, quando retira da responsabilidade do financiador a possibilidade de vir a responder por qualquer dívida da empresa em que ele realizar aportes, inclusive quando essa vier a pedir recuperação judicial, excluindo expressamente a aplicação do art. 50 do Código Civil 5 .

Dessa forma, não haverão maiores complicações para o caso em que o angel investir em uma startup microempresa ou empresa de pequeno porte, através de um contrato de participação, posto que estaria protegido pela regra do art. 61 -a, § 4o, II da $\mathrm{LC}^{\circ} 155$ para os casos de litígios na esfera civil.

Por outro lado, nos casos em que se operar mediante outros contratos o investimento, a exemplo do contrato de mútuo ou da sociedade em conta de participação, esse risco seria maior, vez que não se aplicaria essa blindagem da norma especial. Além do mais, na SCP é possível atrair o investidor, que na qualidade de sócio oculto, poderá responder pela dívida da startup, isso porque pode o sócio ostensivo, na qualidade de investido, estender a sua responsabilidade, conforme a regra disposta no art. 991 do CC/02. Nessa esteira, Nery Junior (2013, p. 1023) dispõe que:

\footnotetext{
${ }^{4} \S 4^{\circ} \mathrm{O}$ investidor-anjo:
}

II - não responderá por qualquer dívida da empresa, inclusive em recuperação judicial, não se aplicando a ele o art. 50 da Lei $\mathrm{n}^{\circ} 10.406$, de 10 de janeiro de 2002 - Código Civil;

5 Art. 50. Em caso de abuso da personalidade jurídica, caracterizado pelo desvio de finalidade, ou pela confusão patrimonial, pode o juiz decidir, a requerimento da parte, ou do Ministério Público quando lhe couber intervir no processo, que os efeitos de certas e determinadas relações de obrigações sejam estendidos aos bens particulares dos administradores ou sócios da pessoa jurídica. 
4. Características. Além das características naturais que têm todas as sociedades, são próprias da sociedade em conta de participação: a) participação do sócio oculto em negócio comercial de outrem (sócio ostensivo); b) inexistência de eficácia societária externa; c) participação do sócio oculto nos ganhos e nas perdas da sociedade.

É nesse sentido, que poderá o fundador da startup, caso se sinta injustiçado, convocar, através de contrato que possui com o investidor, o angel para se solidarizar com o débito exigido, onde ainda que o credor não tenha ciência da existência do sócio oculto, seja realizada a comunhão da dívida, desde que estejam preenchidos os pré-requisitos do art. 50 do CC/02, nos casos em que o débito for de natureza cível.

Importante registro deve ser feito com relação à opção da startup e do investidor-anjo com relação ao modelo contratual escolhido para operar um investimento. Isso porque, embora a LC $\mathrm{n}^{\circ} 155$ preveja o contrato de participação como mais uma possibilidade e não uma imposição do legislado; se utilizar de caminho diverso não deve ser interpretado como violação das regras empresariais e, portanto, requisito legitimador a usurpar a autonomia da personalidade jurídica para alcançar o patrimônio dos sócios, conforme a teoria maior do art. 50 do CC.

O Superior Tribunal de Justiça já tem precedente sobre litígio parecido. Trata-se do REsp 1.658.648/SP, em que um consumidor pessoa física adquiriu uma motocicleta da empresa HDSP Comércio e Representação de Veículos Ltda, a qual além de ter sido entregue fora do prazo acordado, apresentou defeito.

Assim, o consumidor lesado ajuizou demanda visando o rompimento contratual, e a devolução dos valores pagos, acrescidos das indenizações pelos prejuízos materiais, com despesas de taxi, revisão do veículo e danos morais. O pedido foi julgado improcedente em primeiro grau, mas reformado pelo tribunal e mantida a condenação. Já em sede de execução, foi requerida a desconsideração da personalidade jurídica, em função da ausência de bens passíveis de penhora do réu e pelo encerramento irregular da PJ.

O incidente foi acolhido pelo juízo, que incluiu na execução os sócios da HDSP: New York Participações e New Point Administração, além de Paulo Izzo Neto (Paulo Neto), e penhorou valores que esse último tinha a receber em outros processos judiciais.

A lide entra rota de convergência com este trabalho a partir da situação discutida em juízo pelo executado Paulo Neto. Isso porque este apresentou impugnação sob a alegação de não ser sócio das empresas executadas, o que foi rejeitado pelo juiz da causa, que entendeu este ser administrador e representante legal das empresas atingidas.

Foi impetrado o respectivo agravo de instrumento por Paulo Neto, que foi rejeitado pelo tribunal de origem, sob a fundamentação de haver manifesta relação de consumo entre as partes litigantes, atraindo, dessa forma, a aplicação da teoria menor prevista no art. 28 do CDC, o que tornaria dispensável o desvio de finalidade e a confusão patrimonial. Assim, mediante recurso especial, a discussão chegou ao STJ, cuja discussão dessa corte merece destaque.

Sendo acolhido parcialmente o recurso, no qual se reformou a decisão dos juízos inferiores, cujo argumento vencedor foi o de que somente o art. 50 do CC poderia responsabilizar o administrador que não é sócio da PJ, e que o art. 28, § $5^{\circ}$, do CDC não possibilita estender os efeitos da desconsideração da PJ para o administrador.

A manifestação do STJ é provida de razão, posto que se legitima pela inteligência legal. Isso porque a questão discutida na corte superior não foram os requisitos para justificar ou não a desconsideração da personalidade jurídica, mas sim a possibilidade de incluir um administrador não sócio como réu num processo de execução.

A disregard doctrine é aplicada para as relações jurídicas civil-empresariais em sua modalidade maior, de modo que para esses casos se torna medida excepcional, onde o alcance dos bens dos sócios ou administradores só está legitimado diante de abusos, mediante desvio de finalidade ou confusão patrimonial. Ou ainda por fraude causada a terceiros. Dessa forma já decidiu o STJ nos REsp 1.526.287/SP e EDcl no AREsp 960.926SP. 
Assim, seria possível pelo art. 50 do CC atingir administrador não sócio pelas relações praticadas pela PJ, diante de atos irregulares. Nesse sentido, o Enunciado $7^{\circ}$ da jornada de Direito Civil de 2002, do Conselho da Justiça Federal, dispõe que: “só se aplica a desconsideração da personalidade jurídica quando houve prática de ato irregular, e limitadamente, aos administradores ou sócios que nela hajam incorrido".

A teoria menor da desconsideração da personalidade jurídica, por sua vez, foi acolhida pelo CDC, em seu art. $28^{\circ}$. Assim, os requisitos exigidos para a sua configuração são menos rígidos, bastando a comprovação de haver prejuízos para o consumidor. Todavia, tal instituto não tem o poder de alcançar bens de administradores não sócios da PJ desconsiderada.

Além do mais, a norma específica de relações de consumo, CDC, não trouxe em seu bojo tal possibilidade, ficando a extensão para administradores não sócios apenas para relações regidas pelo $\mathrm{CC} / 02$, de modo que não merece prosperar interpretação extensiva da teoria menor para aplicar um dispositivo que além de não previsto pela norma em vigor, houve previsão quando da elaboração do CDC, mas houve veto presidencial, indicando claramente a opção do legislador pela não aplicação desse trecho para as relações consumeristas. Nesse sentido, a doutrina de Zelmo Denari (1999, p. 208), comenta:

$\mathrm{O} \S 1^{\circ}$ do art. 28 - vetado pelo Presidente da República - dispõe que "a pedido da parte interessada o juiz determinará que a efetivação da responsabilidade da pessoa jurídica recaia sobre o acionista controlador, o sócio majoritário, os sócios-gerentes, os administradores societários e, no caso de grupo societário, as sociedades que o integram". Nas razões de veto encaminhadas ao presidente do Senado Federal, presidente da República considera que "o caput do art. 28 já contém todos os elementos necessários à aplicação da desconsideração da personalidade jurídica, que constitui, conforme doutrina amplamente dominante do Direito pátrio e alienígena, técnica de repressão a práticas abusivas". Da leitura se infere que, por um equívoco remissivo, o veto recaiu sobre o $\S 1^{\circ}$ quando, de modo coerente, deveria versar seu $\S 5^{\circ}$ que - com excessivo rigor e desprezando os pressupostos da fraude e do abuso de direito previstos no caput do art. 28 - desconsidera a pessoa jurídica "sempre que sua personalidade for, de alguma forma, obstáculo ao ressarcimento de prejuízos causados aos consumidores".

Também foi nesse sentido a interpretação do STJ no voto do relator que foi o vencedor na turma:

$\mathrm{O}$ art. 50 do CC, que adota a teoria maior e admite a responsabilização do administrador não sócio, não pode ser analisado em conjunto com o $\S 5^{\circ}$ do art. 28 do CDC, que abraça a teoria menor, pois este exclui a necessidade de preenchimento dos requisitos previstos no seu caput permitindo a desconsideração da personalidade jurídica de forma menos rígida, por exemplo, pelo simples inadimplemento e pela ausência de bens garantidores do pagamento do débito. (STJ, 2017).

Dessa forma, não restam dúvidas que a desconsideração da personalidade jurídica quando for utilizada para satisfazer dívidas que a startup contrair em relações consumeristas deverá se utilizar exclusivamente da teoria menor regulamentada pelo art. $28^{\circ}$ do CDC, sem caber interpretação extensiva para alcançar patrimônio de terceiro administrador, mas não sócios, conforme autoriza o art. 50 do Código Civil, mas apenas para relações civis-empresariais.

Vencido esse ponto, o segundo questionamento se trata com relação à aplicação da relativização da personalidade jurídica, com base no CDC para alcançar o patrimônio do investidor-anjo, nos casos em que a sua vinculação com a startup for através de um contrato de participação, sob as égides da LC $\mathrm{n}^{\circ} 155$. Isso porque a norma complementar é silente sobre a responsabilidade do financiador diante das relações consumeristas decorrentes da corporação com os seus clientes, nos casos em que a companhia figurar como fornecedora de produto/serviço, e na outra ponta o comprador/usuário for destinatário final, configurando essa relação consumerista.

Segundo o art. 61-a, $\S 4^{\circ}$, II, fica afastada a desconsideração da PJ prevista no CC/02, que conforme pacificação doutrinária e jurisprudencial, tem aplicabilidade exclusiva para as relações civis-empresariais, sem, contudo, posicionar-se sobre o que dispõe o microssistema consumerista sobre eventual incidente. 
Tal questionamento é demasiadamente palpitante, haja vista que a $\mathrm{LC}^{\circ}{ }^{\circ} 155$ se trata de legislação recente, promulgada no ano de 2016, cujos fatos ainda começando a ocorrer no mundo dos fatos, e através de consulta realizada nos sítios nacionais de jurisprudência, nenhum precedente judicial foi encontrado sobre o assunto.

Aparentemente, não há choque legislativo entre o CDC e a LC n ${ }^{\circ}$ 155/16 de modo que é possível a vigência simultânea de ambos regramentos, com exceção de uma pequena parte da legislação consumerista, pelos motivos a seguir.

Segundo o art. $2^{\circ}$, $\S 1^{\circ}$ da Lei de Introdução às normas do Direito Brasileiro, só haverá substituição de norma, nas seguintes hipóteses: i) lei nova expressamente declara; ii) leis incompatíveis; iii) lei nova regular inteiramente a matéria que tratava a lei anterior.

Ora, a LC 155/16 não declarou expressamente a substituição do CDC, conforme fez no art. 61-a, § $4^{\circ}$, II ao se referir especificamente à norma do CC/02 no art. 50, de modo que resta superada a sua aplicabilidade para as relações civis-empresariais, blindando o angel para débitos decorrentes desses vínculos. Há, portanto, uma omissão legal, que deve ser interpretada como aplicável o dispositivo do CDC.

Ainda sobre o que dispõe a LINDB, não há incompatibilidade de normas entre o CDC e a LC nº 155/16, sendo plena a convivência pacífica e simultânea de ambos os regramentos. Isso também, porque a terceira hipótese de regulamentação total de lei nova não aconteceu, onde a norma que regula o investimento-anjo embora seja mais recente que o CDC, não se propôs nem de longe a regular inteiramente uma relação consumerista, de maneira que também restam superadas as outras duas possibilidades da LINDB.

Nesse sentido, é possível concluir que a Lei n ${ }^{\circ}$ 155/16 não se posiciona sobre as relações jurídicas consumeristas contraídas pela startup, em sentido diverso do que faz com relação ao art. 50 do Código Civil, onde expressamente afasta a sua aplicabilidade através do seu art. $61-\mathrm{a}, \S 4^{\circ}$, II. Assim, diante dessa omissão do legislador, quando interpretada com as orientações fornecidas para a hermenêutica legal da LINDB, é possível concluir que não há revogação do dispositivo da desconsideração da personalidade jurídica, na modalidade da teoria menor prevista no CDC, para as dívidas contraídas pela startup, quando de natureza consumerista, para alcançar o patrimônio do investidor-anjo, quando vinculado à empresa devedora mediante um contrato de participação.

Entretanto, a LC n ${ }^{\circ} 155 / 16$ afasta parcialmente a aplicabilidade do art. 28 do CDC, no que se refere ao ponto "A desconsideração também será efetivada quando houver (...) estado de insolvência" (Brasil, 2016). Isso porque, segundo aquela norma, a redação do art. 61-a, $\S 4^{\circ}$, II é expressa ao afastar além do art. 50 do CC/02, também as hipóteses em que a startup passar por um processo de recuperação judicial: “ $\$ 4^{\circ} \mathrm{O}$ investidor-anjo: II - não responderá por qualquer dívida da empresa, inclusive em recuperação judicial (...)" (Brasil, 2016, grifos nosso).

Nesse sentido, há antinomia, haja vistas que o CDC estende a possibilidade de desconsideração da PJ para os casos em que houver estado de insolvência da empresa, o que estaria configurado na hipótese de uma corporação requerer a sua recuperação judicial, onde o estado de insolvência pode ser momentâneo.

A Lei $n^{\circ} 11.101$ de 2005 regula o procedimento de recuperação judicial, tendo como objetivo evitar a falência da companhia, possibilitando a recuperação do equilíbrio financeiro da mesma, dispondo como escopo final, conservar a função social que essa desempenha em função das diversas relações que ela proporciona em uma comunidade. Assim, a tentativa de recuperar a sanidade da companhia, é possível que no momento do pedido, a situação seja de insolvência, com dívidas superiores às receitas, mas exista possibilidade de reverter esse quadro, seja através de uma melhoria na gestão, mudança nos quadros econômicos nacionais e internacionais capazes de afetar a produção da mesma, mas que configuraria a hipótese prevista pelo CDC.

Assim, a companhia estaria ao mesmo tempo protegida pela regra da LC 155/16, mas também exposta pelo dispositivo do art. 28 do CDC, em virtude do seu estado de solvência. Todavia, aparentemente não há maiores dificuldades em solucionar 
tal confusão hermenêutica, onde além de ser norma mais recente, é também texto mais específico a legislação que regula o contrato de participação para investidores-anjos, fazendo com que houvesse a blindagem destes quando operarem um investimento através da modalidade contratual prevista pela LC 155/16, afastando a incidência parcial do CDC, exclusivamente para a hipótese de estado de insolvência.

A responsabilidade decorrente das relações trabalhistas é diversa da aplicada pela legislação civil. Se trata de um microssistema jurídico, dotado de regras e princípios próprios, o qual se assemelha bastante com a disposição consumerista. Isso porque, também parte da presunção de hipossuficiência de uma das partes, que no caso laboral é o trabalhador, e tem como principiologia fundamental, atuação do estado para buscar a equalização desse relacionamento.

Em matéria de responsabilidade civil, foi feita uma interpretação sistêmica para a aplicação desse instituto sobre as relações trabalhistas. Isso porque, muito dos dispositivos utilizados nos processos trabalhistas, são previstos em normas gerais, a exemplo da regulação do incidente de desconsideração da personalidade, que a reforma trabalhista inseriu na CLT o art. 855-

A, remetendo para o CPC a maneira de como deve-se proceder:

Artigo 855-A. Aplica-se ao processo do trabalho o incidente de desconsideração da personalidade jurídica previsto nos arts. 133 a 137 da Lei no 13.105, de 16 de março de 2015 - Código de Processo Civil. (Brasil, 2017).

O TST, através da Instrução Normativa 39, em seu art. $6^{\circ}$ pacificou a questão acerca da aplicação subsidiária do CPC para tal incidente. Assim, embora não haja mudança material sobre o fenômeno da desconsideração da personalidade jurídica nos processos trabalhistas, com a remissão para o CPC, o incidente passou a ser processado em procedimento que suspende o processo, abrindo prazo para a produção de provas e contraditório para os empregadores, o que em certa parte pode dificultar em alguma medida a efetividade da superação da PJ. Vide art. 855-A da CLT:

$\S 2^{\circ} \mathrm{A}$ instauração do incidente suspenderá o processo, sem prejuízo de concessão da tutela de urgência de natureza cautelar de que trata o art. 301 da Lei no 13.105, de 16 de março de 2015 Código de Processo Civil. (Brasil, 2017).

Embora a CLT seja omissa sobre quais são os parâmetros materiais para a aplicação desse instituto, os juízes trabalhistas aplicam para as relações de emprego a regra da Teoria Menor, prevista no art. $28^{\circ}$ do CDC, sob fundamentação no princípio da igualdade substancial, em virtude de serem sistemas com parâmetros e axiologias similares: proteção e hipossuficiência de uma das partes da relação.

A doutrina se posiciona nesse sentido, a qual tem em Maurício Goudinho Delgado (2014, pp. 504-505) parâmetro para essa tese:

O advento da nova regulação do direito de empresa pelo código civil, reestruturando a anterior sociedade por cotas de responsabilidade limitada (arts. 1052 a 1065, CCB/2002), não tem o condão de modificar o já sedimentado posicionamento jurisprudencial trabalhista. O novo $\mathrm{CCB}$ até mesmo explicita a incorporação da teoria da desconsideração da personalidade jurídica, há décadas já adotada, com leitura própria, no âmbito laborativo. (...) Na seara justrabalhista a noção de despersonalização da figura do empregador é, sem dúvida, mas ampla, de maneira a assegurar a efetividade dos direitos sociais fundamentais trabalhistas também pelo patrimônio dos sócios das entidades societárias, em caso de frustração da execução com respeito ao patrimônio da respectiva sociedade empregadora independentemente de comprovação de fraude ou vícios congêneres na gestão empresarial ou no uso da fórmula da pessoa jurídica.

Nesse sentido já decidiu o TST. Destaca-se: "Na esfera trabalhista, aplica-se ainda a Teoria Menor da Desconsideração da Personalidade Jurídica, prevista no art. 28 do CDC, em razão de se identificar no trabalhador a mesma situação de hipossuficiência do consumidor" (TST, 2016). 
Dessa forma, quando se estiver diante de casos em que um investidor-anjo se utilizar do modelo de contrato de participação para investir em uma startup, ele não terá maiores responsabilidades sobre dívidas decorrentes de demandas trabalhistas, e essa aparenta ser uma questão que não demanda maiores discussões.

A LC 155/16 veda ao angel, dentre outras coisas: i) integrar o capital social da empresa; ii) a gerencia ou voto sobre a administração da empresa. Dessa forma, diante de situações regulares que obedeçam a esses dispositivos, a blindagem do investidor estaria garantida, porque embora o sistema trabalhista atue na direção do trabalhador, a CLT estabelece a necessidade de ligação mínima entre a pessoa que poderia ser responsável e o empregador, a exemplo de administração conjunta ou sociedade em comum.

Dessa forma, restaria inviabilizado o redirecionamento da dívida trabalhista para alcançar o patrimônio do investidoranjo contratado pela LC 155/16. Entretanto, não é possível concluir o mesmo, quando a operacionalização do investimento-anjo ocorrer através de outro contrato, a exemplo da SCP ou no mútuo conversível. Isso, porque de maneira geral, segundo CC/02, seria possível a convocação do sócio oculto para responder pelas dívidas da empresa.

Todavia, diante dos casos de sucessão trabalhista, onde se opera a alteração subjetiva do contrato de trabalho na figura do empregador, ocorre simultaneamente a transferência para o novo empregado de todos os débitos trabalhistas oriundos do empreendimento que está agora sob sua nova administração.

É que segundo os arts. 10 e 448 da CLT, a alteração na estrutura jurídica ou na propriedade da empresa não poderá prejudicar os contratos de trabalho vigentes na época anterior à alteração subjetiva.

Art. 10 - Qualquer alteração na estrutura jurídica da empresa não afetará os direitos adquiridos por seus empregados.

Art. 448 - A mudança na propriedade ou na estrutura jurídica da empresa não afetará os contratos de trabalho dos respectivos empregados. (Brasil, 1943).

Assim, em homenagem aos princípios da intangibilidade objetiva do contrato de emprego, continuidade da relação de emprego e despersonalização dos empregados, os encargos trabalhistas se transferem com junto com sucessão de titularidade dos ativos empresariais. Nesse sentido, é a orientação jurisprudência 261 do TST $^{6}$, que ao julgar demanda relativas a bancos, deixou consolidada o entendimento de que as obrigações trabalhistas são de responsabilidade do sucessor, todas as vezes em que se operar transferência de ativos, agencias, direitos e deveres contratuais.

Além do mais, ainda que não exista continuidade na prestação dos serviços, e ocorrer o encerramento do vínculo de emprego entre empresa sucedida e os empregadores que laboravam antes da nova titularidade empresarial, o sucessor se torna responsável pelas obrigações trabalhistas provenientes dos contratos de trabalho extintos antes da sucessão. Foi esse o entendimento adotado pelo TST (TST - RR: 2559520125040261, Relator: Maria Helena Mallmann, Data de Julgamento: 20/11/2018, 2 $2^{\text {a }}$ Turma, Data de Publicação: DEJT 23/11/2018).

Nessa linha, o art. 10-A provoca implicações para os casos de investimento mediante aquisição de participação societária. Embora se trata de modalidade financiamento mais arriscada, onde o investidor passa a integrar o capital societário, essa opção de outra via possibilita uma maior ingerência sobre os rumos da empresa, haja vista que enquanto no contrato de

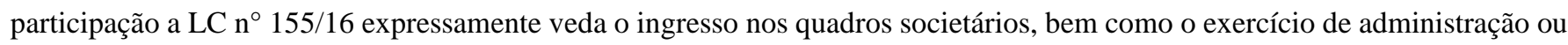
gestão da companhia, ao operar mediante uma aquisição de quotas da empresa, o investidor passa a ser voz ativa para as tomadas de decisões da companhia.

\footnotetext{
${ }^{6}$ BANCOS. SUCESSÃO TRABALHISTA. Inserida em 27.09.02 As obrigações trabalhistas, inclusive as contraídas à época em que os empregados trabalhavam para o banco sucedido, são de responsabilidade do sucessor, uma vez que a este foram transferidos os ativos, as agências, os direitos e deveres contratuais, caracterizando típica sucessão trabalhista.
} 
Segundo o trecho supracitado da CLT, a responsabilidade do sócio retirante da empresa passa a ser subsidiária e limitada ao período em que ele figurou como integrante da companhia, onde passa a correr o prazo decadencial de dois anos após a averbação do contrato da sociedade para o trabalhador que queira pleitear judicialmente algum direito violado.

Ficou estabelecida também uma ordem de preferência de execução, onde deve-se seguir obrigatoriamente a ordem: 1) empresa devedora; 2) sócios atuais; 3) sócios retirantes. Assim, houve uma blindagem para os sócios retirantes em matéria trabalhista, onde agora o juízo exequente deverá apenas subsidiariamente responsabilizar o patrimônio pessoal do ex-membro da empresa, e apenas para os débitos que sejam contemporâneos ao momento em que esse ostentou a natureza societária.

Para isso, todavia, um longo percurso deve ser percorrido, posto que apenas com a frustração da satisfação da dívida pelo patrimônio da empresa devedora, dos sócios atuais, para que ao fim, se alcance o espólio do retirante.

Na relação jurídica tributária, o órgão político estatal precisa de recursos financeiros para manter toda a sua estrutura, voltada prioritariamente para a satisfação da coletividade, sempre no interesse do bem em comum. Nesse sentido, a principal fonte de arrecadação de valores é feita através da cobrança de tributos.

Assim, dentro de todo o regramento estabelecido para o Direito Tributário, com destaque para o princípio da legalidade, o qual advém do art. 150, I da Constituição Federal, estabelece a vedação para a "União, aos Estados, ao Distrito Federal e aos municípios: I - exigir ou aumentar tributo sem lei que estabeleça” (Brasil, 1988).

Nesse sentido, todas as vezes que um ente federativo brasileiro for instituir ou majorar um tributo, terá que, dentro competência tributária determinada pelo texto constitucional, o fazê-lo mediante lei.

A norma tributária irá estabelecer uma hipótese abstrata, chamada de hipótese de incidência, que quando praticada no plano da realidade, será chamado como fato gerador, o qual adequa o fato à norma, constitui uma obrigação tributária, a qual compõe de um lado o sujeito ativo, que é o estado credor do objeto dessa relação que é o pagamento do tributo, e do outro, temse como regra o contribuinte, como sendo a pessoa que diretamente praticou o fato previsto em lei, ou diante das hipóteses legais, tem-se o responsável tributário.

Trata-se, portanto, de um ramo jurídico do Direito Público, onde há dentro de um dos polos da relação o Estado como sujeito ativo, credor do objeto dessa conexão, e do outro um contribuinte ou responsável tributário, responsável pela satisfação da dívida.

De acordo com o art. 113 do Código Tributário Nacional (CTN), “a obrigação tributária é principal ou acessória” (Brasil, 1966). Todavia, aquela que interessa ao presente trabalho é a principal, isso porque enquanto a obrigação acessória consiste em prestações positivas ou negativas, meras obrigações de fazer, como por exemplo emissão de notas fiscais, o dever de escriturar os registros e livros contábeis da empresa, declarar os rendimentos, entre outros.

Por sua vez, a responsabilidade principal, que surge através da prática do fato gerador, tem como objeto uma obrigação de dar, o pagamento de tributo ou penalidade pecuniária, que é o pagamento de valores.

O sujeito passivo da obrigação tributária é aquela pessoa que se encontra na posição de devedor, a qual poderá ser uma pessoa física ou jurídica, que muito embora suporte o ônus do encargo gerado, pode ter sido quem participou diretamente da operação que constituiu o dever, que seria o contribuinte de direito, ou alguém que, embora não tenha participado diretamente da atividade tributária, a lei atribuiu a responsabilidade pelos encargos decorrentes. Essa é a lição de Maria Rita Ferragut sobre o tema:

Contribuinte é a pessoa que realizou o fato jurídico tributário e que cumulativamente encontar-se no polo passivo da relação obrigacional. Se uma das duas condições estiver ausente, ou o sujeito será o responsável, ou será o realizador do fato jurídico, mas não o contribuinte. Praticar o evento, portanto, é condição necessária para essa qualificação, mas insuficiente (Ferragut, 2013, p. 33, grifos nosso). 
Assim, percebe-se que enquanto o contribuinte possui uma relação pessoal e direta com a prática do fato gerador, o responsável tributário possui uma relação indireta com o vínculo, cuja figura é regulada pelo capítulo V, arts. 128 a 138 do CTN. É assim que diz o art. 128 do Código Tributário Nacional, quando atribui a responsabilidade do crédito a terceira pessoa, que, embora não tenha praticado o fato gerador, guarde com ele alguma vinculação:

Art. 128. Sem prejuízo do disposto nesse capítulo, a lei pode atribuir de modo expresso a responsabilidade pelo crédito tributário a terceira pessoa, vinculada ao fato gerador da respectiva obrigação, excluindo a responsabilidade do contribuinte ou atribuindo-a a este em caráter supletivo do cumprimento total ou parcial da referida obrigação. (Brasil, 1966).

Assim, haja vista que é o elemento e o instituto pelo qual se pode fazer com que alguém que, embora componha o quadro societário, ou até mesmo não esteja formalmente inscrito na sociedade, pode se tornar encarregado do ônus tributário decorrente das obrigações contraídas pela empresa.

Nesse sentido, há se abordar o risco e a responsabilidade que o investidor-anjo pode ter perante a startup pela qual ele aportou recursos na qualidade de financiador da mesma. Em função das diversas modalidades de sua atuação, diversos são os impactos decorrentes da sua escolha. Isso porque, conforme exposto previamente, é possível que, ainda que a startup esteja formalmente constituída, com personalidade jurídica própria, portanto, com capacidade para contrair obrigações e deveres em nome próprio, existem possibilidades legais, pelas quais o fisco brasileiro se agarra, para adimplir a obrigação.

Nos casos em que o investidor-anjo integrar formalmente os quadros da sociedade, a desconsideração da personalidade jurídica da empresa faria com que o seu patrimônio fosse alcançado mais facilmente, vez que a startup estaria na qualidade de contribuinte de direito da obrigação tributária, através de uma sucessão, atingindo o seu patrimônio.

Segundo a LC 155/16, o art. 61-A possibilitou que o investidor-anjo seja uma pessoa física ou jurídica, que traz uma série de ônus e bônus para o angel, que caso opte por operar mediante essa lei, deverá se utilizar do contrato de participação, sem poder integrar a sociedade, haja vista que há vedação expressa dessa norma para a sua participação no quadro societário. Contudo, a possibilidade trazida por essa legislação se trata de mais uma opção disponível para operar o investimento, de modo que ela não esgota todas as possibilidades existentes.

Nesse sentido, o mesmo entendimento, portanto, deve ser seguido para os casos em que o angel optar pelo contrato de mútuo conversível, antes de eventual conversão da dívida em participação societária, ou ainda da sociedade em conta de participação, que é oponível apenas entre as partes contratantes, não se tornando, portanto, integrante da startup, nos casos retrocitados.

Ainda sobre a SCP, merece ser reforçado o entendimento de que o eventual contrato que exista entre o investidor e a startup não seria suficiente para atrair àquele a responsabilidade pelas obrigações contraídas pela empresa, sobretudo em relação ao fisco. Isso porque é da inteligência do art. 123 do CTN, que deixou demasiadamente claro que a impossibilidade de acordos privados, feito entre particulares, repercutir na esfera pública tributária, haja vista que apenas a lei tem o poder distribuir ônus fiscais.

Art. 123. Salvo disposições de lei em contrário, as convenções particulares, relativas à responsabilidade pelo pagamento de tributos, não podem ser opostas à Fazenda Pública, para modificar a definição legal do sujeito passivo das obrigações tributárias correspondentes. (Brasil, 1966).

Nesse sentido, tanto o Estado cobrador, quanto a startup interessada em estender a responsabilidade da obrigação tributária, estariam impedidos de se utilizar de uma SCP para incluir o investidor que não integrar formalmente os quadros 
societários da empresa para ser responsabilizado, afastando dessa forma o dispositivo do incisivo VII art. 134 do CTN que estende a responsabilidade para terceiros, como os "os sócios, no caso de liquidação de sociedade de pessoas".

Interessante discussão, todavia, levanta-se, para os casos em que, embora não sejam sócios da startup, pessoa que integraria a eventual relação tributária na qualidade de contribuinte, os investidores não possuiriam relação direta e pessoal com o fato gerador da obrigação. Contudo, os devidos esclarecimentos devem ser dados com relação à hipótese prevista pelo art. 124, inciso I do CTN, que regula a solidariedade na obrigação tributária.

Segundo esse dispositivo, a solidariedade se estende para "as pessoas que tenham interesse comum na situação que constitua o fato gerador da obrigação principal”, onde a expressão “interesse comum na situação", por ser demasiadamente vaga, abriu um leque de possibilidades enormes, favorecendo o fisco.

Além do mais, um fato interessante sobre a peculiaridade da relação tributária é que, nesse segmento jurídico, a própria legislação já abriu a possibilidade de se alcançar o patrimônio de terceiros não contribuintes, ou pessoas que não praticaram o fato gerador e que não possuem relação direta e pessoal com o objeto do vínculo, tornando desnecessária a instauração do incidente de desconsideração da personalidade jurídica prevista no art. 133 do CPC/15, que seria feito em juízo.

Assim, à própria fazenda já é facultada a possibilidade de na constituição da dívida ativa, estender a responsabilidade para terceiros, redirecionando a execução fiscal para outros não contribuintes. Assim, o Estado pode, através do processo administrativo que irá lançar o crédito tributário e iniciar a persecução tributária, independente de autorização judicial, desde que preenchidos os requisitos legais, ampliar o polo passivo da dívida. Inclusive, já há entendimento no STJ nesse sentido, conforme os julgados AREsp 1.173.201/SC, AgInt no REsp 1.646.648SP e REsp 1.775.269-PR.

Sobre esse último julgamento, cabe destaque do que ficou registrado no voto vencedor:

Não é necessária a instauração do incidente de desconsideração da personalidade jurídica (art. 133 do CPC/2015) no processo de execução fiscal no caso em que a Fazenda Pública exequente pretende alcançar pessoa distinta daquela contra a qual, originalmente, foi ajuizada a execução, mas cujo nome consta na Certidão de Dívida Ativa, após regular procedimento administrativo, ou, mesmo o nome não estando no título executivo, o Fisco demonstre a responsabilidade, na qualidade de terceiro, em consonância com os arts. 134 e 135 do CTN (STJ. 1a Turma. REsp 1.775.269-PR, Rel. Min. Gurgel de Faria, julgado em 21/02/2019 (Info 643). (Grifos nossos).

Contudo, como interpretar o que seria o interesse comum, capaz de redirecionar a execução fiscal? Deve-se reforçar, desde já, que o legislador foi muito sensível com a fazenda, ao escolher uma expressão excessivamente vaga e facilmente interpretada em favor do fisco. Ora, porque ter convergência nos interesses é algo que durante uma operação empresarial irá ocorrer com diversas pessoas e em diversos momentos, sem fazer com que isso qualquer terceiro que se aproxime da startup participe da prática do fato gerador que faz acontecer a incidência tributária e, consequentemente, constituir a obrigação tributária, tornando-o responsável pelos encargos decorrentes.

Esses questionamentos chegaram ao Superior Tribunal de Justiça, que através do REsp 884.845/SC decidiu da seguinte maneira:

9. [...] Forçoso concluir, portanto, que o interesse qualificado pela lei não há de ser o interesse econômico no resultado ou no proveito da situação que constitui o fato gerador da obrigação principal, mas o interesse jurídico, vinculado à atuação comum ou conjunta da situação que constitui o fato imponível. (Grifos nosso).

Assim, ficou esclarecido que o interesse comum estará configurado mais pela existência de direitos e deveres idênticos entre a sociedade e terceiros, decorrentes de atuações comuns ou conjuntas na situação jurídica que vier a constituir o fato gerador, que irá atrair a incidência tributária. Ficou ainda afastada a possibilidade de configurar a solidariedade de terceiros apenas pelo mero interesse econômico no resultado ou pelo proveito econômico da situação que vier a constituir o fato gerador. 
Ora, seria exatamente o caso dos investidores-anjo que não se tornando sócios da startup, a sua relação seria de terceiro que possui interesse econômico no resultado ou no proveito da situação que constitui o fato gerador, e que pela inteligência desse julgado do STJ, não se estaria em um primeiro momento legitimando a expansão da responsabilidade para alcançá-lo.

Maria Rita Ferragut oportunamente exemplificou exemplos de interesse comum a solidariedade, como na hipótese do “pagamento do IPTU por todos os proprietários do mesmo imóvel e do ITBI pelas transmissões imobiliárias de interesse tanto do comprador como do vendedor".

Nesse sentido, voltando ao julgado que interpretou o art. 124, I do CTN, que teceu esclarecimentos acerca do interesse comum, o caso em concreto se tratava do litígio entre a Fazenda que tentou executar o grupo econômico Banco Safra S/A, por dívidas tributárias da empresa Safra Leasing S/A Arrendamento Mercantil integrante daquela equipe.

Acontece que se trata de pessoas distintas, com autonomia de vontade e capacidade jurídica próprias. Muito embora o interesse e proveito econômico do grupo econômico fosse bastante latente, por si só não é elemento suficiente para configurar a solidariedade. E foi assim que entendeu o STJ: para configurar o interesse comum do art. 124, I do CTN é preciso que "as pessoas solidariamente obrigadas sejam sujeitas da relação jurídica que deu azo à ocorrência do fato imponível” (REsp 884.845/SC), exatamente para evitar a lógica legal de imputar a terceiro que não possua qualquer relação com o fato gerador da obrigação tributária, a injusta responsabilidade tributária.

\section{Considerações finais}

Ante o exposto, percebe-se que os investidores-anjos passam a ser peças chaves para o crescimento e desenvolvimento das startups. Assim, a experiência em gestão, conhecimento do mercado, de rede de distribuidores ou network proporcionado pelos angels pode levar a startup a um patamar que seria inatingível ou alcançado em um tempo muito maior do que sem eles.

No Brasil, com a aprovação da Lei Complementar $n^{\circ}$ 155/2016, a qual voltada para as Microempresas e Empresas de Pequeno Portes, que visem obter financiamento de investidores-anjos, criou a figura do contrato de participação como mais uma opção para operar esse financiamento.

No entanto, existem infinidades de opções dentro da legislação brasileira para manejar um investimento-anjo, que poderá provocar as mais várias consequências jurídicas, em que se observa a relação jurídica que deu origem ao eventual litígio, a roupagem jurídica da empresa e a natureza jurídica do vínculo que empresa possui com o investidor.

A novidade da temática, a relevância que as startups possuem para o cenário econômico e social, e o papel que os angel possuem dentro desse cenário, são os elementos que compõe e enriquecem o presente manuscrito, a qual se propôs a fazer uma análise de todos esses elementos, proporcionando uma discussão interdisciplinar entre a economia, conhecimentos gerais, atualidades e a ciência jurídica, buscou-se produzir para a comunidade acadêmica e coletiva geral um guia jurídico para as relações que irão decorrer desse ecossistema.

Assim, tendo como base a axiologia constitucional, e partindo para uma hermenêutica sistêmica com a legislação civil e normas esparsas, foram feitas análises e ponderações acerca da distribuição de responsabilidades entre investidor e investido dentro do que a legislação orienta sobre como deve ser. A pluralidade de possibilidades legais, em alguns momentos o surgimento de antinomias, são embaraços que podem confundir a cabeça de quem se interessa em ingressar nesse mercado, proporcionando em algum percentual, certa insegurança jurídica.

A blindagem feita pela LC 155/16 para o angel que investir através de um contrato de participação é aplicável para a regra prevista no art. 50 do CC/02, mas apenas uma pequena parte do art. 28 do CDC foi afastada em virtude daquela legislação. Todavia, se o financiamento ocorrer mediante um contrato de mútuo, uma sociedade em conta de participação ou aquisição de 
participação societária, haverão consequências diferentes, mais prejudiciais para o investidor, aumentando a sua responsabilidade, mas possibilitando uma maior ingerência sua sobre a gestão da investida.

Os tribunais, sobretudo o STJ e o TST, já deram algumas decisões que podem servir de precedente para as startups quando tiverem algum litígio em matéria de responsabilidade jurídica em virtude de relação cível, consumerista, tributária e trabalhista, e esses julgados foram analisados neste trabalho.

Dessa maneira, percebe-se que o direito brasileiro estabeleceu um pêndulo, que em algum momento pede para o investidor e em outro pende para a startup. Isso porque na medida em que confere maior ingerência para o angel sobre a startup, fazendo com que dela participe na qualidade de sócio, gestor ou administrador, as suas responsabilidades irão crescer consideravelmente perante eventual desconsideração da personalidade jurídica.

De outro lado, quando lhe for cassadas tais prerrogativas, esse deverá se contentar com o mero retorno dos rendimentos dentro do que foi acordado no contrato de participação previsto pela LC n ${ }^{\circ} 155 / 16$.

Por fim, pontua-se que a abordagem realizada, discutida e escrita neste manuscrito, espera-se levar o projeto adiante, tendo em vista a extrema relevância das startups para o crescimento econômico e a geração de emprego e renda, acreditamos que investigações como esta devem ser prosseguidas. Sendo assim, como sugestão para continuidade de discussões nesse sentido, analisar, à luz do Direito Empresarial, de que modo as inovações normativas tratam acerca das startups e o investidor-anjo, contribuirá para o fortalecimento e planejamento de estratégias de atenção a este segmento.

\section{Referências}

Becho, R. L. (2014). A responsabilização tributária de grupo econômico. Revista Dialética de Direito Tribturário, n. 221.

Coelho, G. T., \& Garrido, L. G. (2016). Dissecando o contrato entre startups e investidores-anjo. In: Júdice, L. P. (org.). Direito das Startups. São Paulo: Juruá. Comparato, F. K., \& Salomão Filho, C. (2008). O poder de controle na sociedade anônima. (5ª . ed.): Forense.

Constituição da República Federativa do Brasil de 1988. http://www.planalto.gov.br/ccivil_03/constituicao/constituicao.htm

Dantas, M. da R. R. (2018). Grupos econômicos e a responsabilidade tributária em execuções fiscais. (1 ${ }^{\text {a }}$. ed.): Noeses.

Decreto-lei $n^{o}$ 5.452, de $1^{\circ}$ de maio de 1943. http://www.planalto.gov.br/ccivil_03/decreto-lei/del5452.htm

Delgado, M. G. (2014). Curso de direito do trabalho. (13a ed.), LTR.

Ferragut, M. R. (2013). Responsabilidade tributária e o Código Civil de 2002: Noeses, 2013.

Lei Complementar $n^{o}$ 155, de 27 de outubro de 2016. http://www.planalto.gov.br/ccivil_03/leis/lcp/lcp155.htm

Lei $n^{o} 13.467$, de 13 de julho de 2017. http://www.planalto.gov.br/ccivil_03/_ato2015-2018/2017/lei/113467.htm

Lei $n^{\circ} 5.172$, de 25 de outubro de 1966. http://www.planalto.gov.br/ccivil_03/leis/15172compilado.htm

Lei $n^{o}$ 8.078, de 11 de setembro de 1990. (1990). Institui o Código de Defesa do Consumidor. http://www.planalto.gov.br/ccivil_03/LEIS/L8078.htm

Marques, C. L. (2006). Contratos no Código de Defesa do Consumidor. (5a . ed.): Revista dos Tribunais.

Nery Junior, N. (2013). Código civil comentado. (10ª . ed.): Revista dos Tribunais.

STJ - REsp: 1658648 SP 2017/0014927-4, Relator: Ministro MOURA RIBEIRO, Data de Julgamento: 07/11/2017, T3 - TERCEIRA TURMA, Data de Publicação: DJe 20/11/2017.

Tartuce, F. (2016). Direito Civil, v. 1: Lei de Introdução e Parte Geral. (12ª ed.): Forense, 2016.

TST - AIRR: 519320135150072, Relator: Cláudio Mascarenhas Brandão, Data de Publicação: DEJT 15/08/2016. 